J. Fayyad, E. G. Karam Institute for Development, Research, Advocacy and Applied Care, Department of Psychiatry and Clinical Psychology, St George Hospital University Medical Center and Faculty of Medicine, Balamand University, Beirut, Lebanon

J. Alonso Health Services Research Unit, Institut Municipal d'Investigació Mèdica, Barcelona, Spain

K. Demyttenaere Department of Neurosciences and Psychiatry, University Hospitals Gasthuisberg, Leuven, Belgium

J. M. Haro Sant Joan de Déu-SSM, Fundacio Sant Joan de Déu, Sant Boi de Llobregat, Barcelona, Spain C. Lara Instituto Nacional de Psiquiatria, Universidada Autonoma Metropolitana, Mexico City, Mexico

J.-P. Lépine Hospital Fernand Widal, Paris, France A. M. Zaslavsky Department of Health Care Policy, Harvard Medical School, Boston doi: 10.1192/bjp.191.5.457a pleasurable activities might approximate a substitute and produce more accurate retention figures. With the high cost of freeze-dried heroin, as used in the UK, adding these incentives might attract funding for a suitably modified study conducted here. Given that high retention rates are today's centrally defined most desirable outcome in the UK, this sort of study might be even more attractive here.

Haasen, C., Verthein, U., Degkwitz, P., et al (2007) Heroin-assisted treatment for opioid dependence: randomised controlled trial. British Journal of Psychiatry, 19I, 55-62.

A. Al-Adwani Great Oaks Mental Health Unit, Ashby, Scunthorpe, North Lincolnshire DNI6 2JX, UK. Email: al-adwani@ntlworld.com

R. Nahata Great Oaks Mental Health Unit, Scunthorpe, UK

doi: 10.1192/bjp.191.5.458

\section{Heroin-assisted treatment: no difference in treatment retention}

Haasen et al (2007) report highly significant findings from their trial of heroin plus methadone maintenance. A small problem is that the heroin plus methadone group were, to a large extent, self-selected, with only $2.3 \%$ failing to initiate treatment in this group $v .28 .8 \%$ in the methadone only arms. They state that this 'limiting effect ... is minimised' by randomisation and intention-to-treat analysis. Intention-totreat analysis makes their already significant findings even more impressive, but randomisation is limited by the unavoidable self-selection in a trial which is necessarily not masked. The paper goes on to say that 'retention was higher in the heroin group, with $67.2 \%$ completing the 12 month treatment compared with $40 \%$ of the methadone group', but later this is given as $56.3 \%$ for the methadone only group when the $28.8 \%$ who did not initiate treatment were excluded. The retention rate would rise again if the drop-out ('discontinued') rate was calculated using the same reduced denominator, and therefore retention rates would possibly differ insignificantly. Taking this into consideration would also explain the almost equal numbers of 'discontinued' participants in the two main arms of the trial.

The findings of this aspect of the trial are not surprising and without doubt it would be difficult to devise a control with the reinforcing power of heroin. Injectable methadone, financial incentives or raise an important issue when evaluating the outcome of maintenance treatment, namely how to evaluate the retention rate in an unmasked trial. The special incentive for patients randomised to methadone treatment was the option to switch to the heroin group after completing 1 year of treatment. Since retention is considered one of the main outcome measures for maintenance treatment, our trial shows that heroin-assisted treatment has two advantages: it reaches a higher number of potential patients (percentage initiating treatment) and the retention rate of those initiating treatment is significantly higher $\left(68.3 v\right.$. $56.3 \%, \quad \log$ rank $\chi^{2}=14.1$, $P<0.001)$. Therefore, it is incorrect to say that 'retention rates would possibly differ insignificantly': the difference is certainly

C. Haasen Department of Psychiatry, University Medical Center Eppendorf, Hamburg, Germany. Email: haasen@uke.uni-hamburg.de doi: 10.I192/bjp.191.5.458a

\section{Factors in those who repeatedly self-harm}

We read with interest the article on young people who self-harm (Young et al, 2007) but feel the outcome of factors considered would have been more viable if a further subgroup analysis was performed in those patients who repeatedly self-harm. A significant amount of our time is taken up by people who self-harm repeatedly. This subset of clients are often entrenched in their behaviour patterns and use services disproportionately. Existing studies have not adequately analysed factors responsible for repetition of self-harm and we feel that Young et al missed an excellent opportunity to investigate this, albeit in a younger agegroup.

An analysis of our data from the Integrated Care Pathway (Rajwal \& Gash, 2006) showed repetition rates of $40 \%$ for 2004, $42 \%$ for 2005 and $43 \%$ for 2006 of all our referrals each year. This means that $18 \%$ of our patients in $2004,18.9 \%$ in 2005 and $19.2 \%$ in 2006 were responsible for the above statistics year on year. These data are from adults of working age and only include repetition in the same calendar year. About $13 \%$ of our referrals are under 21 , and $18 \%$ of those are for repetitions of self-harm. Hence a small proportion of our clients are responsible for a large proportion of our work.

Our data support Young et al on the less, but still significant. lack of a gender bias in the prevalence of self-harm. Females comprised $50.2 \%$ of our referrals in 2006 but only $49.0 \%$ of those repeating self-harm. The old myth of a higher proportion of females self-harming was not borne out by our statistics, although we considered the entire adult age-group.

We would be interested to know whether the results of Young et al would be different in the subgroup with repeated self-harm.

Rajwal, M. \& Gash, A. (2006) Risk assessment in selfharm. Psychiatric Bulletin, 30, 436.

Young, R., Van Beinum, M., Sweeting, H., et al (2007) Young people who self-harm. British Journal of Psychiatry, 191, 44-49.

M. Kripalani Bath Villa Annex, St Luke's

Hospital, Middlesbrough, UK. Email: drmukesh@doctors.org.uk

R. Badanapuram, A. Gash, S. Morris

St Luke's Hospital, Middlesbrough, UK

doi: I0.II92/bjp.I9I.5.458b

Authors' reply: Kripalani et al raise an important issue by suggesting that those who repeatedly self-harm may constitute a distinctive clinical subgroup. We initially avoided including this group in our study because there remains considerable uncertainty about an appropriate definition. However, following discussion with $\mathrm{Dr}$ 